118. April 5, 1897;0.1 g. cannabinol regenerated from acetyl compound. Taken at 11 A.M., tired and sleepy in afternoon. 119. April 10, 1897; $0.2 \mathrm{~g}$. cannabinol regenerated from acetyl compound. Taken at 1 r.M., slight dryness of mouth and paresthesia $(160 \mathrm{~m}$.) followed by sleepiness, depressed during evening, retired at $11: 30$.

120. A pril 13, $1897 ; 4$ cannabinol tablets (a commercial preparation) g. cannabinol. Taken at 5:08 P.M., feeling of lightness in head $(5: 55)$, dinner $6: 00$, afterward felt sleepy and elightly intoxicated; time relations altered but not annulled.

121. June 7, 1897; 0.2 g. cannabinol phosphate. Taken at $10: 30$ P. .. , Retired at 12 M. . no evident effect.

122. June 9, 1897; 0.4 g. cannabinol phosphate. No distinct action.

123. June 6, 1897; $0.8 \mathrm{~g}$. cannabinol phosphate. Taken at $10: 45$ P.м., $11: 40$ very sleepy, retired, awoke at $7: 20$ A. M., feeling vory sleepy, depressed all the morning.

124. March 17,$1898 ; 0.05 \mathrm{~g}$. oily extract of charas, containing .013 g. soluble products. Dinner at $6: 20$, taken at $8: 00$, slight sleepiness and mental exhaustion followed.

125. March 18,$1898 ; 0.105 \mathrm{~g}$. oily extract of charas, containing $0.13 \mathrm{~g}$. soluble products. Taken at $6: 25$ P. .., dinner $6: 50$, $7: 35$ peculiar feeling of lightness in head, continued to work, $8: 00$ rather better, $11: 00$ retired feeling sleepy.

126. March 20,$1893 ; 0.016 \mathrm{~g}$. (1/4 grain) ext. cannab. Ind. (B. P.) pill. Tea 5 P.M., slight indigestion, pill taken at $7: 30$, $10: 30$ no evident effect, $10: 35$ slight light-headedness, warmth of face and mental exhaustion, afterward fell asleep.

127. March 21, $1898 ; 0.14 \mathrm{~g}$. partly (3/4) saponified acetyl derivative of higher homologue of cannabinol. Taken at $5: 30$ P.M., no effect.

128. March 22, 1898; $0.1 \mathrm{~g}$. third fraction cannabinol. Taken at $5: 45$ P.M., dinner $6: 30,8: 25$ feeling of lightness in head and mental exhaustion, continued working, effect passed off in about $30 \mathrm{~m}$.

129. March 23, 1898; 0.1 g. second fraction cannabinol. Taken at $5: 45$ P.M., dinner $6: 45,7: 20$ no effect, $9: 25$ slight dryness of lips and lightness in head, seemed to pass off but worse again at $7: 43$, happy, have difficulty in reading, sleepy, $10: 00$ just awakened from a short nap, read a little but soon exhausted, $11: 20$ retired, $6: 45$ A.M. awoke, felt well.

130. March 24, 1898; $0.1 \mathrm{~g}$. first fraction cannabinol. Taken at $5: 45$ P.M., dinner $6: 45,7: 45$ no effect, $7: 50$ feeling of slight dryness of lips and lightness of head, 8:00 somewhat more depressed, not working well, $8: 45$ working better. 10:00 still somewhat depressed, $11: 30$ retired but did not succeed in sleeping for some time.

131. March 25, $1898 ; 0.1$ g. cannabinol (oldest). Taken at $5: 45$ P.M., dinner at $6: 30,7: 30$ peculiar light-headedness and dryness of the lips, $7: 45$ slightly unsteady, parasthesia in head and legs, heaviness of eyelids, no correct estimation of time, $9: 30$ awakened from short sleep, 10:00 rather better but unable to work, $10: 30$ retired, somewhat depressed the following morning.

132. March 27,$1898 ; 0.35 \mathrm{~g}$. acetyl derivative of higher homologue of cannabinol. Taken at $7: 30$ P.M., no effect.

133. March 29,$1898 ; 0.05$ g. cannabinol pill made 18 months ago. Taken at $5: 50$, dinner at $6: 30,8: 30$ unsteady symptoms, cannot work, estimation of time not so good, $9: 15$ worse, ener gyless, $10: 30$ went out for few minutes, improved, $11: 00$ can read moderately well but eyelids heavy.

134. March 30, 1898; $0.09 \mathrm{~g}$. Merck's cannabinon. 'Taken at $5: 45$, dinner $6: 30,7: 20$ lightness in head, loss of time relation, happy, amused, pleasant tingling. etc. ; sleeny, 8:00 lay down, slept till 10:30 then retired, awakened ( $7: 00$ A.M. ) feeling dull and depressed, lasted the whole morning.

135. A pril 14, 1898;0.05 g. opium. Taken at 9:00 P. M., $10: 00$ no obvious action, $10: 05$ glight heaviness of eyelids, very slightly tired, $10: 20$ rather better, $11: 10$ feel somewhat tired head rather heavy, slight sense of "well-being," 12:00 still heaviness of eyes and tiredness of head but have worked fairly well last half hour, not sleepy; retired, soon fell asleep, awakened at $7: 00 \mathrm{~A}$. $\mathrm{s}$. feeling well, pleasant sense of gravity which continued most of morning; no constipation.

136. A pril 15, 1898; $0.1 \mathrm{~g}$. cannabinol through which oxygen passed 3 to 5 hours at 150 to 160 degrees $C$. Taken at $5: 45$, dinner at $6: 30,9: 15$ slight visual indefiniteness, slight and tran sient paresthesia, afterward felt slight incapacity for work but no marked effects, $11: 45$ not sleepy but retired.

137. April 17, $1898 ; 0.05 \mathrm{~g}$. cannabinol sealed up since Dec. 28 , 1896. Tea $4: 30$, drug taken $5: 45,6: 50$ slight mental exhaustion and feeling of lightness in head, $7: 20$ rather sleepy, 8:00 trying to read but have little energy for anything, 9:00 condition same, no estimation of time, feeling of warmth in face and head, 10:00 sleepy, retired.

138. A pril 21,$1898 ; 0.065 \mathrm{~g}$. same cannabinol treated with oxygen for 20 hours at 150 to 185 degrees $C$. Taken at $5: 45$, dinner 6:40, 8:05 slight feeling of lightness in head, $9: 30$ have been reading some time, at first had a little difficulty, now feel quite normal.

139. April 22, $1898 ; 0.05$ g. same cannabinol treated with $\mathrm{CO}_{2}$ for 20 hours at 150 to 185 degrees $C$. Taken at $5: 50$, dinner $6: 30,7: 00$ commencing light-headedness. $8: 00$ more distinct, a want of energy, 9:45 condition same, trying to read, 10:00 not able to do any work, 10:45 no improvement, retired. 140. April 24, 1898: $0.1 \mathrm{~g}$. tribrom-cannabinol. Taken at $8: 00$ P.M., supper at $8: 30,9: 30$ slightly sleepy, $11: 00$ sleepy, no other peculiar effect of cannabinol, retired, slept till $6: 45$, depressed, suffered from mental exhaustion during three following days.

141. May 4, $1898 ; 0.065$ g. oxycannabinol (as in 138) dissolved in oil. Taken at $5: 45$, dinner at $6: 30$. $7: 15$ went out for a walk, 8:15 arrived home, slightly tired, peculiar feeling in eyes and head grew slightly worse and continued the whole evening, but was insufficient to prevent me writing; 11:10 retired, slept soundly, $6: 40$ A.M. got up, felt sleepy.

142 May 6,$1898 ; 0.1$ g. charas (best). Taken at $5: 45$, tea at $4: 30$, dinner at $7: 00,7: 00$ slight effect in head, worked in garden, felt want of energy, 8:30 influence more marked, agreeable heaviness of eyelids, very little energy, 10:00 retired, condition same, slept well, depresed following morning.

143. May 12, $1898 ; 0.016 \mathrm{~g}$. ( $1 / 4$ grain) ext. cannab. Indic (B. P.) in pill (cp. 126). Taken at $5: 50$, dinner at $6: 30,7: 25$ lightress of head, peculiar feeling about eyes, $7: 50$ pleasant tingling in face and feet, no other marked effect, reading fairly well, 8:40 tingling still present, unable to read with benefit, can not calculate time very well, symptoms continued through. out evening, became sleepy but managed to do some copying, $12: 30$ retired, $7: 30$ got up feeling tired but soon well.

144. May 19,1898 ; 2 c.c. sesqui terpene taken in weak mucilage. Taken at 12:45, lunch $1: 10,1: 15$ slightly listless and slight heaviness of head, which soon passed away.

\section{THE THERAPEUTICAL ECONOMICS OF OPEN COMPOSITION.}

Presented to the Section on Materia Medica, Pharmacy and Therapeutics, at the Forty-ninth Annual Meeting of the American Medical Association, held at Denver, Colo., June 7-10, 1898.

BY ALBERT B. PRESCOTT, M.D.

ANN ARBOR, MICH.

There is only one restriction upon the character of medicines supplied to the public, to be expected at the hands of the law-makers in the period now before us, namely: restriction, with the intent to put a stop to concealment of composition and identity. That legal restriction to this effect may be instituted in some of the States at any time, and is likely to become prevalent, appears manifest from the temper of the law-making mind, shown in various ways, especially in the scope of the enactments against adulterations. Any alteration of composition is prohibited if it be not made known to the purchaser (or consumer), but is allowed if it be so made known. Various irregular admixtures are specifically authorized upon the one condition that they shall be explicitly announced on the label. On the other hand, various colorings and facings of food, which are harmless in themselves, are prohibited because they tend to deceive the consumer as to identity or quality of the article. The same intent appears in legal rulings for uniform standards of concentration of foods and of medicines, and it appears in the early requirements of poisonlabels, lately extended, in some instances, to proprietary mixtures sold without a physician's order and without any account of contents.

Granting that some of these prohibitory measures have been worked for as a means of protection to certain industries, and that in other cases the legislation has been proposed by unscrupulous persons, who seek opportunity to levy bribes, etc., it still remains true 
that the laws already enacted in this direction have been made possible by a prevailing conviction in the minds of common-sense people, holding as they do, the ultimate balance of power in legislation, that it is dangerous to leave covers of concealment over articles of medicine or food in the market. The average intelligent citizen, and the average plain man of the law, when the question is put fairly before him, will say without hesitation that medicines sold in packages, without the direction of a physician, ought to be compelled by law to bear a statement of their contents in terms known to science. This average man of sense will maintain that it is no affair of the State whether an article of medicine purchased in the market be pharmacopeial or not, made by patented or concealed processes or not, trade-marked by a proprietor or not, monopolized in production or not, but that it does matter to the man who is to take the article of medicine or give it to his child, whether or not he shall be informed what the article really is, in terms such as any physician or pharmacist could define and interpret; and furthermore, that the right of the man to this information might well be made an affair of the State. In fact, the layman is likely to enforce a classification of therapeutic agents, more simple than any of the systems known in pharmacology, a mere division of medicaments into the knowns and the unknowns. And legislative enactment is more than liable to separate the one of these divisions from the other "as a shepherd divideth his sheep from the goats," when these matters are brought into judgment.

With this outlook, therefore, the concern of this brief paper is not one of professional ethics, but rather one of social economics. Neither the physician nor the pharmacist has any economic interest in the use of secret remedies, or any reason to delay prohibitory measures against secrecy of composition. The custom of medication by remedies named from the diseases they are alleged to cure is a custom that has no actual use for pharmacists or physicians at all.

The physician within whose function it falls to select remedies and confine their application to certain needed results, may, in his discretion, either countenance or discountenance secrecy of composition. $\mathrm{He}$ is liable to think little of his responsibility in this matter, because while he is acting as an expert for his patient the latter has no need to be informed of the contents of medicinal mixtures. For his own judgment, the physician may believe himself able, in some cases, to arrive at the character of a medicine without a statement of its contents, and may avail himself of the convenience of a ready-made secret mixture, which thenceforth holds the benefit of his approval.

The pharmacist, on the contrary, is not to judge of the selection and application of remedies of his own knowledge as an expert, neither'is he to question his patron's choice among various systems of medication. So long as articles of concealed composition are not made contraband in law, it is difficult for the pharmacist to refuse to furnish them, especially difficult when they are directed by physicians. He can only do so upon the ground that such articles can not be made subject to record, as to the identity and quantity of the distinct agents they contain,therefore, he can have no check upon them and will not supply them.

While secret medicines are tolerated by the laws, the physician or the pharmacist has but limited re- sponsibility for their use, little influence as to their employment one way or the other. If he do not go beyond his proper province, the secrecy of remedies is not of his doing, nor can he stop the use of these articles by the people. But both the physician and the pharmacist have marked influence, as authorities in regard to medicines in use, and have influence upon law-makers as to legislation in the question of open. composition by the demand of the law.

A policy of prudence, and of courage as well, with a careful study of the bearings of every legal provision proposed on the part of the staunch men of medicine and of pharmacy, can do most effective service in behalf of better economies in medication.

\section{THE MODERN INTESTINAL ANTISEPTICS AND ASTRINGENTS.}

Presented to the Section on Materia Medica, Pharmacy and Therapeutics, at the Forty-ninth Annual Meeting of the American Medical Asso-
ciation, held at Denver, Colo., June 7-10, 1898. BY WM. FANKHAUSER, M.D. NEW YORK.

The last decade has been very fruitful as regards the introduction of intestinal antiseptics and astringents. To comprehensively describe each and every one introduced during this period, would be beyond the scope of a paper the reading of which will not prove tiresome to the listeners. I will therefore confine myself to those which have made their first ap. pearance during the past five or six years. The mod. ern intestinal antiseptics and astringents belong chiefly to one of two classes of preparations: derivatives of tannic acid, or salts of bismuth. The former will be alluded to first, the articles being described in the order of their introduction into the materia medica.

Among internal astringents tannic acid has long occupied a prominent position; but it has a number of serious drawbacks, chief among which is that it acts undesirably on the mucose of the mouth and stomach, where the larger portion of its effect is expended before the remedy reaches the intestines. Prolonged administration of tannic acid, furthermore, is known to be productive of gastric disturbances-anorexia, pain, nausea, and even vomiting. With a view to obviating these disadvantages, experiments have been made with various derivatives of tannic acid, resulting in the production of a number of eligible compounds.

Tannin albuminate was the first preparation introduced, which has a less disagreeable taste than the acid itself and acts less vigorously on the stomach; but, owing to the fact that it is largely absorbed in the latter organ, its astringent action becomes to a great extent lost to the intestine, and for this reason the remedy has been practically abandoned as an antidiarrheal. The dose in which it was given is from 5 to 20 grains, in cachets.

Tannigen was the next preparation brought forward which, with a few of its congeners since introduced, is not acted upon to any great extent in the stomach, and manifests its astringent action chiefly on reaching the slightly alkaline (in health, but in morbid conditions, vastly increased alkaline) secretions of the intestine, where a gradual and equable decomposition ensues and continues to the end of the gut. Tannigen was introduced by Prof. Hans Meyer of the University of Marburg, Germany, in the fall of 1894 (see Deutsche Med. Woch., 1894, No. 31). It is known, 